\title{
BUKU PENGAYAAN CERITA ANAK DWI BAHASA BERMUATAN BUDAYA SEMARANGAN: POTENSI DAN PRINSIP PENGEMBANGANNYA
}

\author{
Rahmatika Rizqi Utami ${ }^{1}$, Nurlaili Irias Putri ${ }^{2}$, Cintia Nugraha ${ }^{3}$ \\ Prodi PBSI, FBS, Universitas Negeri Semarang, \\ rahmatikarizqiutami96@gmail.com¹,nurlailiiriasp@gmail.com²,407cintianugraha@gmail.com³
}

\begin{abstract}
Abstrak
Buku adalah salah satu sarana sumber belajar terbaik bagi anak. Namun yang menjadi masalah jumlah buku cerita anak tidak sebanding dengan jumlah kegiatan yang ada. Padahal banyak sekali cerita unik dan menarik yang bisa dijadikan referensi untuk mengembambangkan buku cerita anak. Misalnya yaitu buku cerita anak dwi bahasa bermuatan kearifan lokal Semarangan. Buku cerita anak dwibahasa mengajarkan anak untuk mengenal bahasa ibu atau bahasa lokal daerah tempat tinggal. Kemudian kearifan lokal Semarangan, diambil karena Semarang memiliki beragam budaya yang unik dan menarik. Budaya Semarangan adalah akulturasi dari tiga kebudayaan yang menyatu yaitu Cina, Arab dan Jawa. Cerita anak bermuatan kearifan lokal mengandung moral value (Nilai karakter) yang sangatlah beragam. Misalkan toleransi, gotong royong, kekeluargaan dan lainya. Buku cerita anak dianggap sebagai Gerakan Literasi Sekolah yang paling mudah dan menyenangkan, karena buku cerita yang disajikan adalah buku cerita yang memiliki kandungan dan kebudayaan kearifan lokal yang multikultural. Metode Penelitian yang digunakan yaitu metode Research and Development. Diperlukan adanya research terhadap kebutuhan anak terhadap seberapa besar minatnya terhadap buku cerita anak untuk kemudian baru dikembangkan menjadi buku cerita anak yang utuh berkearifan lokal. Dalam implementasinya terdapat empat prinsip pengembangan buku pengayaan cerita anak bermuatan kearifan lokal Semarangan, yakni: berdasarkan aspek isi, penyajian, bahasa, dan grafika.
\end{abstract}

Kata kunci: buku pengayaan, gerakan literasi sekolah (GLS), cerita anak.

\begin{abstract}
Abstrack
Books are one of the best sources of learning for children. But the problem is the number of children's storybooks is not proportional to the number of activities that exist. Though a lot of unique and interesting stories that can be used as a reference to embody children's storybooks. For example, the bilingual children's storybook containing local wisdom Semarangan. Bilingual storybooks teach children to recognize the mother tongue or the local language of the area of residence. Then local wisdom Semarangan, taken because Semarang has a unique and interesting cultural diversity. Semobangan Culture is the acculturation of the three cultures that are united, namely China, Arab and Java. Children's stories are filled with local wisdom contains a very diverse moral value. Suppose tolerance, mutual cooperation, kinship and others. Children's story books are considered the School Literacy Movement is the easiest and fun because the storybook presented is a storybook that has
\end{abstract}


the content and culture of multicultural local wisdom. The research method used is Research and Development method. Required a research on the needs of children on how much interest in children's storybooks to then just be developed into a child storybook intact local wisdom. In the implementation, there are four principles of the development of children's story enrichment book containing local wisdom Semarangan, namely: based on aspects of content, presentation, language, and graphics.

Keywords: Enrichment book, school literacy movement (GLS), children’s story,

\section{PENDAHULUAN}

Buku merupakan bahan bacaan yang digunakan dalam Gerakan Literasi Sekolah (GLS). Bahan bacaan yang digunakan termasuk dalam jenis bacaan nonpelajaran. Tujuan dari GLS adalah untuk menumbuhkan budi pekerti peserta didik melalui pembudayaan ekosistem literasi sekolah yang diwujudkan dalam GLS. Hal tersebut didukung oleh Kementerian Pendidikan dan Kebudayaan yang menerbitkan Peraturan Menteri Pendidikan dan Kebudayaan Nomor 23 Tahun 2015 tentang Penumbuhan Budi Pekerti. Salah satu hal pokok yang tertuang dalam peraturan tersebut yaitu kewajiban membaca buku nonteks pelajaran selama 15 menit sebelum jam pembelajaran dimulai setiap hari di sekolah (Tempo, 2017).

Kegiatan 15 menit membaca tersebut dilakukan sebelum pembelajaran dimulai. Pada semua jenjang pendidikan mendapatkan tugas yang sama untuk membaca sebelum pembelajaran berlangsung. Akan tetapi, ada beberapa hambatan dalam pekalasanaanya. Menurut penelitian yang dilakukan oleh Akbar (2017), kurangnya buku sumber hingga buku cerita menjadi kendalanya. Pendapat ini didukung dengan beberapa contoh cerita anak berupa sastra anak yang didominasi oleh buku cerita terjemahan. Contohnya Seri Mickey kelompok Disney, Seri Boneka Binatang karya Tony Wolf, Seri Rose Selarose, Seri Mini Noddy, Seri Noddy, dan sebagainya. Data kecil ini menyiratkan bahwa sedikitnya sastra anak Indonesia mengakibatkan larisnya sastra anak versi terjemahan (Sugihastuti, 2011).

Buku cerita anak menjadi salah satu bahan bacaan yang diperlukan pada jenjang sekolah dasar. Pilihan buku ini memiliki manfaat bagi pembaca anak dalam mencapai tujuan penumbuhan budi pekerti anak. Hal ini didukung oleh pendapat Nurgiyantoro (2013) yang menyatakan bahwa karakteristik cerita fiksi anak memiliki citra kehidupan yang dapat dipahami sebagai penggambaran secara konkret tentang model-model kehidupan yang sesungguhnya di dunia sehingga mudah diimajinasikan oleh pembaca anak. Oleh karena itu, cerita anak dapat menyampaikan nilai budi pekerti dalam cerita yang digambarkan secara konkret.

Kekurangan buku bacaan akan terjadi ketika stok bahan bacaan tidak bertambah. Akan tetapi kegiatan dilakukan secara terus menerus. Akibatnya, tidak ada variasi bahan bacaan bagi peserta didik. Fenomena ini yang perlu adanya tindakan untuk mengatasinya. Salah satu solusinya dengan mengembangkan buku bacaan yang disesuaikan dengan karakteristik pembaca dan sesuai dengan fungsi GLS sebagai gerakan peningkatan literasi di Indonesia. Kesesuaian tersebut dapat berupa muatan kearifan lokal dan bahasa daerah dalam buku cerita. Pemilihan karifan lokal bertujuan untuk menyisipkan nilai budi pekerti dalam wujud kearifan lokal.

Potensi kearifan lokal yang unik salah satunya dimiliki daerah Semarang. Semarang adalah 
salah ibu kota provinsi di Jawa Tengah yang juga memiliki kearifan lokal yang kaya dan cukup unik. Hal itu dikarenakan dalam perkembangan kearifan lokal Semarang sangat dipengaruhi oleh bentuk kearifan lokal pembauran yang berasal dari Jawa, Arab, dan Cina. Pembauran ini terjadi karena Semarang merupakan daerah pusat perekonomian yang mempertemukan tiga suku tersebut. Asimilasi itu secara otomatis membentuk kearifan lokal tersendiri yang dapat berupa kearifan lokal asli maupun gabungan.

Di sisi lain, bahasa daerah digunakan sebagai upaya pelestarian bahasa daerah. Berdasarkan pemetaan bahasa di Indonesia oleh Badan Pengembangan dan Pembinaan Bahasa, bahasa daerah yang telah teridentifikasi dan divalidasi sebanyak 652 bahasa dari 2.452 daerah pengamatan. Data ini diambil dari tahun 1990 sampai dengan 2017, terdapat 13 bahasa yang punah, 4 bahasa sangat terancam, 18 bahasa terancam punah, dan 2 bahasa mengalami kemunduran (Data Bahasa Daerah 2017). Hal ini menggambarkan bahwa bahasa daerah sudah tidak lagi dijadikan sebagai bahasa ibu dan tergantikan oleh bahasa Indonesia serta bahasa asing. Selain terbatasnya jumlah buku cerita berbahasa daerah menjadi faktor yang dominan punahnya bahasa daerah di Indonesia (Tempo, 2015). Hal tersebut diperkuat dengan fakta bahwa rata-rata penerbit hanya mencetak 5-10 judul buku berbahasa daerah per tahun. Untuk satu buku dengan cetak awal sebanyak 2.000 eksemplar (Kompas, 2011).

Relevan dengan situasi tersebut serta kebutuhan buku cerita anak yang mendukung Gerakan Literasi Sekolah (GLS), perlu adanya pengembangan buku cerita anak dwibahasa bermuatan kearifan lokal Semarangan. Berdasarkan itu tulisan ini memaparkan potensi buku verita anak dwibahasa bermuatan kearifan lokal Semarangan berdasarkan kebutuhan peserta didik dan guru, serta bentuk dan prinsip buku cerita anak dwibahasa bermuatan kearifan lokal Semarangan.

\section{METODE PENELITIAN}

Metode penelitian yang digunakan dalam penelitian ini yaitu dengan prosedur penelitian Research and Development (penelitian dan pengembangan) dari Borg dan Gall (2003:775) dengan tahap: (a) research and information collecting, (b) planning, (c) develop preliminary form of product, (d) preliminary field testing, (e) main product revision, (f) main field testing, (g) operational product revision, (h) operational field testing, (i) operational product revision, (j) operational field testing (k) final product revision, dan (l) dissemination and implementation. Upaya kebutuhan penelitian ini disesuaikan dengan tujuan dan kondisi penelitian yang sebenarnya. Penelitian ini dihentikan pada langkah kelima berdasarkan pertimbangan bahwa langkah ke-6 sampai 12 dari $R \& D$ Cycle Borg dan Gall, merupakan penelitian lanjutan yang berujung pada penerapan dan diseminasi nasional.

\section{Data dan Sumber Data}

Data berupa skor kecenderungan kebutuhan buku cerita anak dwibahasa. Adapun sumber data analisis kebutuhan diambil dari guru dan peserta didik dua sekolah yang berbeda. Sekolah-sekolah tersebut dipilih berdasarkan karakteristik kearifan lokal Semarangan yang dianut, yakni daerah kota yang diwakili SD Al Madina Semarang, dan daerah pedesaan yang diwakili SD N 1 Sekaran Gunungpati. 


\section{Instrumen}

Bentuk instrumen dalam penelitian ini menggunakan instrumen nontes. Instrumen nontes digunakan untuk menjaring data kebutuhan dan penilaian buku cerita anak dwibahasa yang bermuatan kearifan lokal Semarangan melalui angket kebutuhan siswa. Tahap lanjutan dalam penelitian ini meliputi proses penilaian. Penilaian ditujukan kepada ahli dan penerbit dengan menggunakan angket penilaian kelayakan buku cerita anak.

\section{Teknik Analisis Data}

Teknik analisis data yang digunakan dalam penelitian ini yaitu analisis deskriptif kualitatif melalui pemaparan data dan verifikasi atau simpulan data. Teknik ini digunakan untuk mengetahui kebutuhan terhadap buku cerita anak dwibahasa yang bermuatan kearifan lokal Semarangan, serta penilaian oleh dosen ahli dan penerbit. Pembahasan dalam penelitian ini merupakan hasil dari langkah penelitian tahap pendahuluan yang menghasilkan potensi dan prinsip pengembangan buku cerita anak dwibahasa bermuatan kearifan lokal Semarangan.

\section{HASIL PENELITIAN DAN PEMBAHASAN}

\section{Potensi Buku Cerita Anak Dwibahasa Bermuatan Kearifan Lokal Semarang}

Buku cerita anak dwibahasa yang sesuai dengan karakteristik anak dan bermuatan kearifan lokal memiliki potensi yang tinggi. Potensi tersebut dilihat dari tiga aspek, yaitu 1) sesuai dengan karakteristik pembaca, 2) dwibahasa, dan 3) kearifan lokal. Ketiganya merupakan potensi yang termuat dalam buku cerita anak dwibahasa bermuatan kearifan lokal Semarangan. Berikut ini uraiannya.

\section{1.) Sesuai Karakteristik Pembaca}

Pertama adalah cerita anak yang sesuai dengan karakteristik daerah tempat tinggal anak. Buku tersebut dapat diunggulkan sebagai produk daerah yang bermanfaat bagi anak. Juga dapat menjadi solusi dari kurangnyaa bahan bacaan. Sehingga dapat mendukung Gerakan Literasi Sekolah (GLS) yang merupakan suatu usaha atau kegiatan yang bersifat partisipatif dengan melibatkan warga sekolah (peserta didik, guru, kepala sekolah, tenaga kependidikan, pengawas sekolah, komite sekolah, orang tua/wali murid peserta didik) akademisi, penerbit, media massa, masyarakat (tokoh masyarakat yang merepresntasikan keteladanan, dunia usaha, dll), dan pemangku kepentingan di bawah koordinasi Direktorat Jenderal Pendidikan Dasar dan Menengah Kementrian Pendidikan dan Kebudayaan (Desain Induk Gerakan Literasi Sekolah, 2016).

\section{2.) Dwibahasa}

Kedua, adalah kedwibahasaan yang digunakan dalam buku cerita anak. Penggunaan bahasa Indonesia dan bahasa Jawa dialek Semarang menjadi kekuatan untuk dapat menguatkan penguasaan bahasa daerah anak. Tujuannya agar anak tidak hanya mahir berbahasa Indonesia saja. Selain itu, buku dwibahasa ini dapat dijadikan salah satu upaya pelestarian bahasa daerah.

Upaya pelestarian tersebut sesuai dengan kondisi masa kini karena keadaan bahasa daerah yang mulai ditinggalkan oleh penuturnya. Berdasarkan pemetaan bahasa di Indonesia oleh Badan Pengembangan dan Pembinaan Bahasa, bahasa daerah yang telah teridentifikasi dan divalidasi 
sebanyak 652 bahasa dari 2.452 daerah pengamatan. Data ini diambil dari tahun 1990 sampai dengan 2017, terdapat 13 bahasa yang punah, 4 bahasa sangat terancam, 18 bahasa terancam punah, dan 2 bahasa mengalami kemunduran (Data Bahasa Daerah 2017). Data tersebut dapat menggambarkan bahwa perlu adanya upaya pelestarian bahasa daerah. Salah satunya melalui buku yang menggunakan bahasa Jawa.

\section{3.) Kearifan Lokal}

Ketiga yaitu penanaman dan pengenalan kearifan lokal yang ada di Semarang. Dalam buku dwibahasa, memuat unsur kearifan lokal dalam cerita yang ditampilkan. Bentuknya berupa nilai, perilaku, dan artefak yang tertuang dalam cerita. Wujudnya dapat berupa perilaku tokoh, setting, maupun amanat dalam cerita.

Kegunaan utama kearifan lokal adalah menciptakan keteraturan dan keseimbangan antara kehidupan sosial, budaya dan kelestarian sumber daya alam (Pattinama, 2009). Berkaitan dengan hal tersebut, maka unsur kearifan lokal menjadi muatan dalam buku cerita anak agar dapat menanamkan nilai-nilai luhur suatu daerah yang digambarkan dalam sebuah cerita. Cerita tersebut mengkisahkan tentang kearifan lokal yang dianut di Semarang. Oleh karena itu, pembaca mendapatkan gambaran nyata melaui tokoh maupun setting yang ada dalam cerita.

Dalam kearifan lokal tersebut terkandung beragam nilai moral; yang menarik pada setiap ceritanya, diantaranya yaitu cerita pertama berjudul " Dugderan Bersama Ayah" yang menceritakan tentang bagaimana penguatan nilai-nilai toleransi dalam sudut pandang 3 kebudayaan disatukan hingga menjadi sebuah kebudayaan baru yang begitu indah dan menarik. Cerita kedua yang berjudul “ Tugu Muda Semuda Kota Semarang Selalu Membawa Cinta” menceritakan petualangan kisah persahabatan keempat anak kecil yang mengingnkan liburannya diisi dengan kunjungan ke berbagai tempat wisata bersejarah untuk merasakan nikmatnya liburan dan juga mendapatkan ilmu pengetahuan. Di dalam cerita tersebut juga disajikan tentang budaya menghargai antar etnis dimana kedua etnis (Jawa dan Cina) disatukan menjadi sebuah keindahan tersendiri. Cerita ketiga berjudul "Liburan Hasil Kebaikan" mengajarkan sikap tanggung jawab dan berbudi luhur dengan menerapkan nilai-nilai kebaikan pada anak sejak dini. Cerita keempat, "Ekspedisi Penjelajahan Budaya Semarang " di mana dalam cerita tersebut digambarkan betapa hebat dan mengagumkannya kearifan lokal budaya Semarangan yang ternyata adalah suatu bentuk peniruaan dari kebudayaan yang sudah ada namun dikemas dengan sesuatu hal yang baru sehingga menghasilkan ciri khas yang sangat unik dan mampu melekat di hati masyarakatanya. Cerita yang terakhir berjduul "Kerjaan Negeri Cina di Semarang" mengisahkan perjuangan pantang menyerah seorang ibu dan anak dalam menghibur orang lain, sehingga didapatkan sebuah hasil yang mengagumkan berupa hadiah yang begitu indah dan hebat.

Dari kelima cerita tersebut selalu bisa diambil hikmah dan pelajaran yang menarik dari setiap sudut pandangnya. Itulah yang membuat buku cerita anak dwibahasa dengan bermuatan kearifan lokal menjadi sebuah potensi yang cukup unik untuk meningkatkan gerakan literasi sekolah, dan menerapkan budaya literasi sekolah sedini mungkin. 


\section{Prinsip Pengembangan Buku Cerita Anak Dwibahasa Bermuatan Kearifan Lokal Semarang}

Pengembangan buku cerita anak dwibahasa didasarkan pada prinsip kelayakan buku (Puskurbuk, 2008). Adapun uraian prinsip-prinsip tersebut dijabarkan dalam empat ciri khusus yakni : isi, penyajian, bahasa dan keterbacaan, dan grafika.

\section{1.) Kelayakan Isi Materi}

Buku cerita anak dwibahasa dapat digunakan bagi peserta didik SD kelas tinggi. Pada aspek kelayakan isi materi dihasilkan prinsip-prinsip pengembangan buku cerita yakni prinsip kesesuaian, bermuatan kearifan lokal Semarang, dan prinsip kemudahan.

\section{(1.) Prinsip Kesesuaian}

Buku cerita anak dwibahasa bermuatan kearifan lokal Semarang ini sesuai dengan karakteristik anak, yakni berdasarkan tempat tinggal mereka. Hal tersebut diaplikasikan pada cerita yang disampaikan memiliki muatan kearifan lokal Semarang. Dengan demikian, buku cerita yang dikembangkan sesuai atau relevan dengan karakteristik mereka.

\section{(2.) Prinsip Bermuatan Kearifan Lokal Semarang}

Pada prinsip ini terdapat integrasi muatan kearifan lokal Semarangan terdapat pada cerita, bahasa yang digunakan, dan ulasan cerita. Integrasi muatan kearifan lokal yang berupa perilaku nilai, perilaku, dan artefak yang dilakukan melalui topik dan latar pada cerita. Jenis budaya Jawa yang dipilih adalah jenis budaya Jawa yang berupa nasihat yang divisualisasikan dalam cerita.

Adapun jenis cerita yang ditampilkan adalah cerita tentang tokoh anak SD. Tokoh dan karakter di dalam cerita dengan penokohan pandai, berjiwa petualang, memiliki rasa ingin tahu tinggi, dan mudah bergaul. Alur yang digunakan adalah alur maju. Latar/setting tempat dan waktu disesuaikan dengan nama tempat tempat wisata dan tempat bersejaran yang ada di Semarang, latar suasana yakni suasana gembira. Tema yang digunakan yakni lingkungan, kegiatan sehari-hari, dan pendidikan. Unsur yang diapresiasi yakni tokoh, penokohan, latar, amanat, dan konflik. Bentuk ulasan yang diaplikasikan berupa ulasan muatan kearifan lokal Semarang yang diulas di masing-masing akhir bab.

\section{(3.) Prinsip Kemudahan}

Pada prinsip ini, buku cerita anak dwibahasa harus mudah dipahami. Berdasarkan hal tersebut maka buku cerita ini dikembangkan dengan mengacu prinsip kemudahan. Prinsip kemudahan ini dikembangkan berdasarkan prinsip-prinsip belajar, yaitu dimulai dari konsep yang mudah dipahami hingga konsep yang susah dipahami. Hal tersebut disesuaikan dengan tingkat pengetahuan dan perkembangan pola pikir peserta didik SD tinggi.

\section{2.) Aspek Kelayakan Penyajian}

Prinsip yang digunakan dalam buku cerita anak dwibahasa bermuatan kearifan lokal Semarang dari aspek kelayakan penyajian meliputi tiga prinsip. Prinsip tersebut yaitu prinsip kemenarikan dan prinsip sistematis. Berikut ini penjelasannya.

\section{(1.) Prinsip Kemenarikan}


Prinsip kemenarikan dalam buku cerita anak dwibahasa ini harus disajikan dengan menarik. Prinsip kemenarikan diaplikasikan dengan cerita yang membuat peserta didik ingin meneladani tokoh-tokoh di dalam ceritanya dan menambah pengetahuan peserta didik dengan informasiinformasi berupa muatan kearifan lokal Semarang. Kemenarikan ini dituangkan dalam ilustrasi, judul, tokoh, dan jumlah halaman yang sesuai dengan pembaca anak.

\section{(2.)Prinsip Sistematis}

Buku cerita anak dwibahasa disusun secara sistematis. Prinsip tersebut diaplikasikan dengan urutan cerita yang runtut sehingga mudah dipahami. Keruntutan penceritaan diaplikasikan dengan cerita yang disajikan secara singkat, setelah itu disajikan ulasan cerita. Penyajian cerita secara induktif agar pembaca anak memahami cerita secara runtut. Kombinasi paragraf dan dialog menjadi variasi yang digunakan agar tidak monoton dalam cerita.

\section{3.) Kelayakan Kebahasaan}

Bahasa merupakan sarana penyampaian dan penyajian materi, seperti kosakata, struktur kalimat, panjang paragraf, dan tingkat kemenarikan sesuai dengan minat dan tingkat pengetahuan peserta didik. Adapun kelayakan kebahasaan berkaitan dengan aspek keterbacaan yang berkaitan dengan tingkat kemudahan bahasa yang meliputi kosakata, kalimat, paragraf, dan wacana.

Adapun penggunaan bahasa dalam cerita adalah dwibahasa (bahasa Jawa dialek Semarang dan bahasa Indonesia). Penggunaan bahasa Jawa bertujuan untuk melestarikan bahasa daerah Semarang. Sedangkan penggunaan bahasa Indonesia bertujuan untuk membantu pembaca memahami cerita. Penggunaan bahasa Indonesia juga berkaitan dengan penyebaran buku apabila pembaca bukan penutur asli bahasa Jawa dialek Semarang. Dua bahasa ini ditampilkan dalam halaman yang berbeda. Halaman sebelah kiri berisi cerita berbahasa Jawa dialek Semarang. Lalu, halaman sebelah kanan menggunakan bahasa Indonesia.

\section{4.) Kelayakan Aspek Grafika}

Penampilan fisik atau kegrafikaan pada buku cerita anak dwibahasa merupakan daya tarik tersendiri yang sangat memengaruhi motivasi peserta didik pada saat membaca. Kelayakan kegrafikaan pada buku cerita anak dwibahasa bermuatan kearifan lokal Semarang meliputi desain buku, kertas dan ukuran buku, tipografi, gambar ilustrasi dan tata letak kulit dan isi buku. Adapun buku cerita anak dwibahasa bermuatan kearifan lokal Semarang dikembangkan berdasarkan prinsip kemenarikan dan prinsip kesesuaian berikut ini.

\section{(1.)Prinsip Kemenarikan}

Sama halnya dengan kelayakan penyajian, pada kelayakan kegrafikaan juga mengacu pada prinsip kemenarikan. Prinsip kemenarikan berkaitan dengan desain isi buku yang meliputi pemberian gambar-gambar yang sesuai dengan ilustrasi, ilustrasi dan layout memiliki warna yang bervariasi, sampul da nisi buku dibuat dengan komposisi ukuran dan warna yang sesuai. Hal-hal tersebut disusun sesuai dengan selera dan perkembangan kognisi peserta didik.

\section{(2.)Prinsip Kesesuaian}

Prisnsip berikutnya adalah kesesuaian. Prinsip kesesuaian berkaitan dengan ilustrasi, ukuran buku, sampul buku, dan jenis huruf. Adapun ilustrasi visual dibuat sesuai perkembangan 
kognisi peserta didik diaplikasikan warna-warna yang terang. Ukuran buku yang sesuai dengan kebutuhan adalah ukuran B5 (176×250 mm); petunjuk penggunaan buku diletakkan di awal buku; sampul menggambarkan isi buku serta tulisan dan gambarnya ditata dengan baik; jenis huruf yang digunakan adalah Times New Roman dengan ukuran 12.

\section{PENUTUP}

Kerarifan lokal Semarangan adalah potensi yang menarik dalam pengembangan buku cerita anak untuk mendukung Gerakan Literasi Sekolah. Kearifan Lokal yang tumbuh dari 3 kebudayaan Cina, Arab dan Jawa menjadi keunikan dan memiliki kekhasan tersendiri dalam implementasinya. Karena dalam percampuran 3 kebudayaan didapatkan banyak nilai-nilai moral yang dipertik. Diantaranya yaitu gotong royong, kekeluargaan dan toleransi. Maka dengan itu buku cerita anak ini diambil berdasarkan latar belakang kearifan lokal dan kedwibahasaan, untuk menumbuhkan serta mengingatkan akan penggunaan bahasa daerah yang sudah mulai luntur bahkan hilang. Dalam implementasinya buku cerita anak dwibahasa ini mengandung 4 prinsip buku cerita anak yaitu dilihat berdasarkan aspek isi, kemenarikan penyajian, kemudahan bahasa, dan kesegaran grafika.

\section{DAFTAR PUSTAKA}

Akbar, Aulia. 2017. Membudayakan Literasi dengan Program 6M Di Sekolah Dasar. JPSD, Maret 2017, 42-52.

Artanti, Artanti (2010) Pembinaan Kesantunan Berbahasa Daerah Sebagai Upaya Pemertahanan Bahasa. In: Seminar Nasional Pemertahanan Bahasa Nusantara, 6 Mei 2010, Hotel Pandanaran Semarang.

Badan Pusat Statistik. 2010. Kewarganegaraan, Suku Bangsa, Agama, dan Bahasa Sehari-hari Penduduk Indonesia. Katalog BPS 2102032.

Bergen, Elsjen Van dkk. 2017. Why Are Home Literacy Environment and Children's Reading Skills Associated? What Parental Skill Reveal. Volume 52, Issue 2.Vrije Universiteit Amsterdam, Belanda.

Boeriswati, Endry. 2017. Persoalan Literasi Abad 21. Makalah pada Konferensi Bahasa dan Sastra II, Semarang.

Borg, W. R and Gall, M. D. 2003. Education Research. New York : Allyn and Bacon. 
Dewi, Ni Wy Budi, dkk. 2014. Model Tematik Bernuansa Kearifan Lokal Berbantuan Media Animasi Berpengaruh Terhadap Hasil Belajar IPA Siswa Kelas III SD Negeri Gugus Kapten Japa. Jurnal Mimbar PGSD Universitas Pendidikan Ganesha Jurusan PGSD Vol: 2 No: 1 Tahun 2014.

Faizah, Dewi Utama. Literasi dalam Pembelajaran. Makalah pada Konferensi Bahasa dan Sastra II, Semarang.

Kompas.com. 2011. Minat Baca Buku Daerah Rendah. http://nasional.kompas.com/

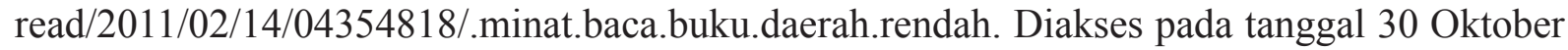
2017.

Nugroho, Deta Dian. 2016. Penegmbangan Buku Cerita untuk Menanamkan Karakter Mandiri dan Peduli Lingkungan Siswa Sekolah Dasar Kelas Rendah. Skripsi. Yogyakarta: Universitas Sanata Darma.

Nurgiyantoro, Burhan. 2010. Sastra Anak: Pengantar Pemahaman Dunia Anak. Yogyakarta: Gadjah Mada University Press.

Permendikbud. 2015. Peraturan Menteri Pendidikan dan Kebudayaan Nomor 23 Tahun 2015 tentang Penumbuhan Budi Pekerti. Jakarta: Depdikbud.

Phelan, James. 2010. “Teaching Narrative as Rhetoric: The Example of Time's Arrow.” In Pedagogy, Volume 10, Issue 1, Winter 2010, pp. 217-228 (Article). Published by Duke University Press.

Sitepu, B.P. 2012. Penulisan Buku Teks Pelajaran. Bandung: Remaja Rosdakarya.

Sugihastuti. 2011. Teori Apresiasi Sastra. Yogyakarta: Pustaka Pelajar.

Tempo.co. 2017. Gerakan Literasi Sekolah Wujudkan Nawa Cita. https://nasional.tempo.co/ $\mathrm{read} / 870509 /$ gerakan-literasi-sekolah-wujudkan-nawa-cita. Diakses pada tanggal 30 Oktober 2017.

Tempo.co. 2015. Perpustakaan Daerah Madura Minim Buku Berbahasa Madura. https://nasional. tempo.co/read/666748/perpustakaan-daerah-madura-minim-buku-berbahasa-madura. Diakses pada tanggal 30 Oktober 2017.

Triyono, Agus. 2012. Inovasi Kota Semarang Membangun Citra Melalui Strategi The Amazing of Java. Proceding Strategi Communication Branding Di Era Industri Kreatif. Jurusan Ilmu 
Komunikasi FISIP Universitas Brawijaya. ISBN 978-602-203-124-0.

Wagiran. 2017. Pelatihan Kurikulum 2013 Versi 2017 MGMP Bahasa Indonesia SMA Kota Semarang. 